\title{
Application of Vinyl ether Copolymers for Surface Modification of Carbon Black
}

\author{
A. V. Perchenok ${ }^{1}$, E. V. Suvorova ${ }^{1}$, A. A. Farmakovskaya ${ }^{1}$, V. Kohlert ${ }^{2}$, \\ ${ }^{1}$ Moscow Aviation Institute (National Research University), \\ Moscow, Volokolamskoe shosse, 4, \\ Russia, \\ ${ }^{2}$ University of Stuttgart, \\ Stuttgart, Pfaffenwaldring, 55, \\ Germany
}

Received: April 8, 2021. Revised: August 31, 2021. Accepted: September 11, 2021. Published: September 14, 2021.

\begin{abstract}
In this work, the possibility of stabilizing aqueous dispersed systems of carbon with vinyl ether copolymers of various composition and structure was investigated. It was shown that the presence of hydrophobic fragments in the macromolecule chain plays a significant role and positively affects the results of stabilization of aqueous dispersions of carbon particles. It was shown that the composition and molecular architecture of the stabilizing copolymer strongly affects the stabilizing ability in studied systems. Studies have shown that the use of a polymeric stabilizer in combination with ultrasonic treatment of dispersed systems makes it possible to obtain stable, homogeneous, highly dispersed suspensions. At the same time, it was demonstrated that a strong increase in the time and intensity of ultrasonic treatment of the system does not lead to a significant improvement in the results.
\end{abstract}

Keywords-Carbon, stability, particles, copolymers, ultrasound.

\section{INTRODUCTION}

$\mathrm{O}$ BTAINING aqueous dispersions of soot of high stability is of undoubted scientific and practical interest. Recently, scientific research has been carried out aimed at increasing the stability and dispersion of suspensions of various pigments using high-molecular and low-molecular surfactants in combination with mechanical activation methods, in particular, processing suspensions in an ultrasound field [1]-[10]. A number of works have published results on the preparation of stable aqueous dispersed systems of nanoparticles using high molecular weight compounds [11]-[26]. The results of these studies are important for obtaining composite materials used in technology [27]-[55].

The presented results show the possibility of using polymer soot surface modifiers to obtain stable aqueous dispersed systems. However, the use of industrially produced polymers for such studies, such as Tegodispers $750 \mathrm{~W}$, Coatex P 90, EHEC, Dispex N 40, Dispex A 40, etc., presents certain difficulties. Commercially available polymers have a very wide MWD, are not always uniform in their composition and molecular weight characteristics, and their composition and structure can partially vary. Therefore, despite a number of indisputable advantages associated with their use, the study of the mechanism of the stabilizing effect on the example of such polymers is hardly capable of providing comprehensive and correct information.

Recent advances in the synthesis of macromolecules of a desired structure (quasi-living radical and ionic polymerization, the use of macromers, etc.) allow to study the effect of subtle differences in the structure of macromolecules (distribution of units in chains of copolymers of various structures) on the properties of synthesized polymers. In this regard, the so-called block copolymers are an interesting class of high molecular compounds [1].

Examination of specially synthesized amphiphilic block copolymers allows to obtain important fundamental information on the effect of differences in the architecture of copolymer molecules on their behavior at the phase interface (solid phase-liquid and liquid-liquid), on their surface activity, on their nano- and microdomain morphology in condensed state. These results, in addition to their fundamental scientific value, can open prospectives for the practical application of such polymers as colloidal stabilizers, modifiers of hydrophobic liquids, fillers and pigments, materials for gas separation and other separating membranes [2-4].

High-intensity ultrasound has found many applications in organic synthesis, materials science and organometallic chemistry, as well as in industrial manufacturing processes. The use of high-intensity ultrasound provides a simple and versatile tool for the synthesis of nanostructured materials that are often unavailable by conventional methods. The main 
physical phenomena associated with ultrasound that are relevant to the synthesis of nanomaterials are cavitation and sputtering. Acoustic cavitation (formation, growth, and instantaneous collapse of bubbles in a liquid) creates extreme conditions inside a collapsing bubble and is the source of most sonochemical phenomena in liquids or liquid-solid suspensions. Another option is atomization (the creation of fog due to the passage of ultrasound through the liquid and hitting the liquid-gas interface), which is the basis of ultrasonic spray pyrolysis (USP) with subsequent reactions occurring in heated mist droplets. Sonochemical phenomena arise from extreme transient conditions caused by ultrasound, which creates unique conditions that can reach temperatures in excess of $5000 \mathrm{~K}$, pressures in excess of 1000 atmospheres, and heating and cooling rates in excess of $1010 \mathrm{~K} / \mathrm{s}$.

The speed of sound in a typical liquid is from 1000 to 1500 $\mathrm{m} / \mathrm{s}$, and the ultrasonic wavelengths can vary from about $10 \mathrm{~cm}$ to $100 \mu \mathrm{m}$ in the frequency range from $20 \mathrm{kHz}$ to $15 \mathrm{MHz}$, which is much larger than the characteristic sizes of molecules. Thus, the chemical and physical effects of ultrasound do not arise from the direct interaction between chemicals and sound waves, but rather from the physical phenomenon of acoustic cavitation: the formation, growth and collapse of cavitation microbubbles. When longitudinal acoustic vibrations of a certain amplitude propagate through the liquid, the liquid is under dynamic tensile stress, and the density changes with alternating waves of expansion and contraction. Discontinuities in the medium (bubbles) are often formed from pre-existing impurities (for example, gas-filled gaps in dust grains) and vibrate with the applied sound field. Bubbles can grow by slowly pumping gas out of the liquid volume into an oscillating bubble (rectified diffusion). Bubbles of a critical size (usually tens of micrometers) can strongly influence the acoustic field and undergo rapid inertial growth during expansion followed by instantaneous collapse. The bubble collapse process is almost adiabatic in its final stages and is the cause of the extreme conditions characteristic of sonochemistry.

There are two main approaches to explaining the energyintensive chemical and physicochemical effects caused by cavitation: thermal and electrical. With the thermal approach, these effects are associated with a high temperature inside the cavitation bubble, achieved during its adiabatic compression with a continuously increasing rate, and with an electric approach, with a discharge inside the bubble due to the accumulation of electric charges on its walls.

Therefore, to obtain more systematic information on the relationship between the structure of the polymer and its surface-active properties, we used a series of tailor-made copolymers with a precisely defined molecular structure and regularly varying parameters.

For the studies, 4 series of block copolymers comprising the methyl vinyl ether (MVE) as a hydrophilic fragment and isobutyl vinyl (IBVE) and octadecyl vinyl ether (ODVE) as a hydrophobic fragment were used. The size of the blocks, their arrangement, molecular weight characteristics of polymers, and other parameters were varied systematically over a quite wide range. The reason for choosing mainly MVE and IBVE block copolymers as stabilizers rather than random copolymers was the previously published results [14], which compared the stabilizing effect of random and block copolymers in aqueous dispersed systems of hydrophobic micro- and nanoparticles. The authors of [17] concluded that the use of random copolymers MVE and IBVE does not allow to obtain a stable dispersed system.

In addition, polymethyl vinyl ether is a thermosensitive ("smart") polymer, its hydrophilic-hydrophobic balance is highly depending on temperature. The transition temperature (LCST - lower critical solution temperature) is $34{ }^{\circ} \mathrm{C}$, and below this temperature the polymer exhibits hydrophilic properties, and above it - hydrophobic properties.

\section{STABILIZATION OF DISPERSED CARBON SYSTEMS WITH DIPHILIC COPOLYMERS}

To obtain more systematic information on the relationship between the structure of an amphiphilic polymer and its surface-active properties, we used a series of new, specially synthesized copolymers with a given molecular structure and regularly varying parameters.

Four types of amphiphilic copolymers of methyl vinyl ether (PMVE) as the hydrophilic moiety and isobutyl vinyl ether (PIBVE) or octadecyl vinyl ether (PODVE) as the hydrophobic moiety were investigated. These copolymers were synthesized by living cationic polymerization on new catalytic systems. The size of the blocks, their location, molecular weight characteristics of polymers, and other parameters varied systematically over a fairly wide range. A series of random copolymers was also used for comparison. For all copolymers used, the value of average molecular weight ranged from 5000 to 8000 , and the degree of polydispersity was from 1,05 to 1,3 ).

The following types of polymers were used (the number in the copolymer formula indicates the degree of polymerization of a given monomer - the number of units in a block):

1) Homopolymers

PMVE 95,

PIBVE 22,

2) Statistical copolymers

PMVE 30 - r - PIBVE 70,

PMVE 50 - r - PIBVE 50,

PMVE 80 - r - PIBVE 20,

3) Diblock copolymers

PMVE 36 - PIBVE 54,

PMVE 43 - PIBVE 10,

PMVE 55 - PIBVE 10,

PMVE 83 - PIBVE 8,

4) Triblock copolymers

PMVE 50 - PIBVE 20 - PMVE 50,

PMVE 62 - PIBVE 10 - PMVE 62,

PIBVE 26 - PMVE 40 - PIBVE 26, 
PIBVE 22 - PMVE 75 - PIBVE 22,

PODVE 4 - PMVE 168 - PODVE 4, PMVE 48 - PODVE 11 - PMVE 48, PMVE 28 - PODVE 10 - PMVE 28.

Using these copolymers as surfactants, studies of the colloidal stability of $0,1 \%$ aqueous dispersed carbon black systems were carried out, and the contact angles of water wetting of the carbon black surface were measured to determine the degree of surface modification by these polymers.

All copolymers used are soluble in ethyl acetate and with the exception of the most hydrophilic PMVE 95 and PMVE 83 - PIBVE 8 are insoluble in water. Therefore, to comply with identical conditions for the preparation of aqueous dispersed systems, the copolymers were preliminarily dissolved in ethyl acetate (polymer concentration - 5\%), and then introduced into the aqueous phase together with the particles (phase ratio $=$ $1: 10)$. Thus, the concentration of polymer was $0,25 \%$.

Special experiments (variation of the volume phase ratio by ethylacetate addition, artificial evaporation of the ethylacetate to compare with ordinary samples) proved that presence of ethylacetate on the initial stage of the preparation did not affect the results on the polymer stabilization activity. After mixing, the systems were treated with ultrasound for $2 \mathrm{~min}$.

Obtaining emulsions with a concentration of $5 \%$ of the mass was carried out under the action of ultrasonic treatment for 2 min with frequency $22 \mathrm{kHz}$ and specific power of $1.5 \mathrm{~W} / \mathrm{cm}^{3}$ with Branson Sonifier B-12 instrument, as well as in a flowthrough mode with an electromagnetic microwave field or a constant electric field with a strength of up to $6 \mathrm{kV} / \mathrm{cm}$. The experimental setup consists from the vessel with immersed sonotrode for ultrasound experiments and the vessel with immersed magnetron for electric field experiments. At the exit from the working volumes, the sizes of emulsion droplets were controlled by dynamic light scattering methods with ZetaSizer Nano instrument. The optical control system allows to determine both the droplet size distribution for transparent emulsions and the average radii of the droplets for cloudy (milk-like) emulsions. Preliminary measurements showed a change in the size of emulsion droplets both when exposed to a microwave field (an increase in the droplet size and subsequent separation of emulsions), and when exposed to ultrasound and a high-voltage constant electric field (a decrease in the average size of droplets and stabilization of the emulsion). These facts allowed to optimize the parameters of emulsions preparation. To ensure the reliability of the experimental results, the experiment was conducted several times with the same parameters and statistics was applied for results treatment.

The ultrasonic treatment resulted in formation of direct $(\mathrm{O}-$ W) microemulsion where all hydrocarbon droplets were located in the ethylacetate microdroplets. After the ethylacetate evaporation at room temperature due to diffusion in water, the polymers were deposited on the hydrocarbon droplets. Replacement of the ethylacetate with other organic solvents (acetone, diethyl ether) did not noticeably change the results of the both types of hydrocarbons.

Special experiments have shown that the presence of ethyl acetate in the system does not affect the stabilizing ability of polymers, but allows more efficient delivery of polymer stabilizers to the surface of organic pigments through the aqueous phase.

Thus, after ultrasonic treatment of the dispersions, a direct type microemulsion was formed, and the pigment particles were in the microemulsion drops. All polymers used at this stage, in combination with the use of ultrasonic treatment as a dispersing action, make it possible to obtain dispersed systems. At the same time, due to the low molecular weight, there is no danger of destruction of these polymers in the ultrasonic field.

\section{RESULTS AND DISCUSSION}

The results of the study of colloidal stability by the sedimentation method are presented in Table 1. As a criterion for assessing the colloidal stability of dispersed systems, the half-settling time of the solid phase was chosen. Contact angle measurements were carried out using the hydrophobic surface and standard optical equipment. To calculate the contact angle, the height and the diameter of the water drops were visually measured.

Table 1. Colloidal stability of aqueous dispersions of carbon black stabilized with polymethylvinylether copolymers.

\begin{tabular}{|l|c|}
\hline \multicolumn{1}{|c|}{ Stabilizer } & $\begin{array}{c}\text { Solid phase semi- } \\
\text { settling time, days }\end{array}$ \\
\hline PMVE 95 & 0,5 \\
PIBVE 22 & 1,5 \\
PMVE 30 - r - PIBVE 70 & 0,2 \\
PMVE 50 - r - PIBVE 50 & 0,3 \\
PMVE 80 - r - PIBVE 20 & 0,4 \\
PMVE 36 - PIBVE 54 & 4 \\
PMVE 43 - PIBVE 10 & 15 \\
PMVE 55 - PIBVE 10 & 70 \\
PMVE 83 - PIBVE 8 & 30 \\
PMVE 50 - PIBVE 20 - PMVE 50 & 8 \\
PMVE 62 - PIBVE 10 - PMVE 62 & 15 \\
PIBVE 26 - PMVE 40 - PIBVE 26 & 30 \\
PIBVE 22 - PMVE 75 - PIBVE 22 & 90 \\
PODVE 4 - PMVE 168 - PODVE 4 & 90 \\
PMVE 48 - PODVE 11 - PMVE 48 & 7 \\
PMVE 28 - PODVE 10 - PMVE 28 & 1 \\
\hline
\end{tabular}

Table 1 shows that homopolymers PMVE 95 and PIBVE 22 do not provide stable aqueous dispersed carbon black systems. Within 10 - 30 hours, there is a rapid sedimentation and destruction of the microemulsion, after 2 days complete settling of pigment particles is observed.

The slight difference between the effects observed for PMVE 95 and PIBVE 22 can be explained by the fact that PMVE 95, being a water-soluble polymer, does not adhere well to the hydrophobic surface of the soot and, in contrast to the hydrophobic PIBVE 22, passes into the aqueous phase, 
thereby promoting particle coagulation.

For diblock copolymers, the colloidal stability of aqueous dispersed carbon black systems depends on the hydrophilichydrophobic balance of the polymer. The dependence of the stability of the dispersed system on the structure of the stabilizer can be represented as the dependence of the semisettling time of the solid phase on the ratio (by the number of units) of the hydrophilic and hydrophobic parts of the macromolecule. From the analysis of the data, it follows that from the point of view of the colloidal stability of aqueous dispersed soot systems, the optimal structure of the stabilizer is a structure with a ratio of hydrophilic and hydrophobic blocks of the order of $5: 1-6: 1$.

These data are presented in the Figure 1.

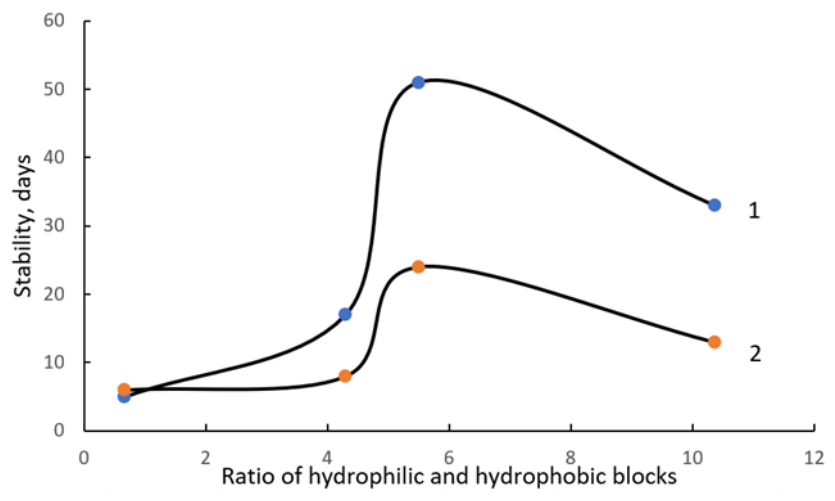

Fig. 1 Dependency of emulsion stability on diblock copolymer composition.

These data are consistent with the data on the contact angles of the carbon black surface treated with PMVE and PIBVE copolymers (Table 2). Comparing them, we can conclude that in the case of using the polymers PMVE 55 - PIBVE 10 and PMVE 83 - PIBVE 8 as surfactants, the better colloidal stability of dispersions corresponds to lower values of contact angles, which indicates the formation of surface layers of these polymers with corresponding properties.

Table 2. Values of contact angles of water wetting of the carbon black surface treated with methyl vinyl ether copolymers.

\begin{tabular}{|l|c|}
\hline \multicolumn{1}{|c|}{ Stabilizer } & $\begin{array}{c}\text { Contact angle of } \\
\text { wetting, degrees }\end{array}$ \\
\hline Without polymer & 124 \\
PMVE 95 & 24 \\
PIBVE 22 & 118 \\
PMVE 36 - PIBVE 54 & 112 \\
PMVE 43 - PIBVE 10 & 91 \\
PMVE 55 - PIBVE 10 & 83 \\
PMVE 83 - PIBVE 8 & 27 \\
PMVE 50 - PIBVE 20 - PMVE 50 & 121 \\
PMVE 62 - PIBVE 10 - PMVE 62 & 46 \\
PIBVE 26 - PMVE 40 - PIBVE & 118 \\
26 & 87 \\
PIBVE 22 - PMVE 75 - PIBVE & \\
22 & \\
\hline
\end{tabular}

Analyzing the data on the colloidal stability of dispersed carbon black systems obtained using triblock copolymers, it can be concluded that the order of arrangement of hydrophilic and hydrophobic blocks in the macromolecule plays a key role. Obviously, only when the hydrophilic PMVE block (even if not very large) is located in the center of the macromolecule, and hydrophobic PIBVE blocks are located at the edges, this polymer has a good stabilizing effect on carbon black dispersions. At the same time, the presence of a hydrophobic PIBVE block in the center of a macromolecule, even not very long, does not make it possible to obtain stable dispersed systems. This effect is especially pronounced for the example of copolymer PMVE 62 - PIBVE 10 - PMVE 62, which is highly hydrophilic in composition, which, having a rather pronounced affinity in the aqueous phase (contact angle is 46 degrees), nevertheless does not exhibit surface-active properties in studied systems. In both cases, the insignificant role of the extreme blocks and their length should be noted. This is in good agreement with the results obtained for the triblock copolymers PMVE and PODVE, as discussed above.

Assumptions about the method of adsorption of polymer stabilizers on the surface of organic pigments can be expressed as follows. Hydrophobic PIBVE (PODVE) blocks are adsorbed on the surface of the organic pigment due to hydrophobic interaction, and the hydrophilic PMVE blocks associated with them are turned into the aqueous phase. This is schematically depicted in the Figure 2. 


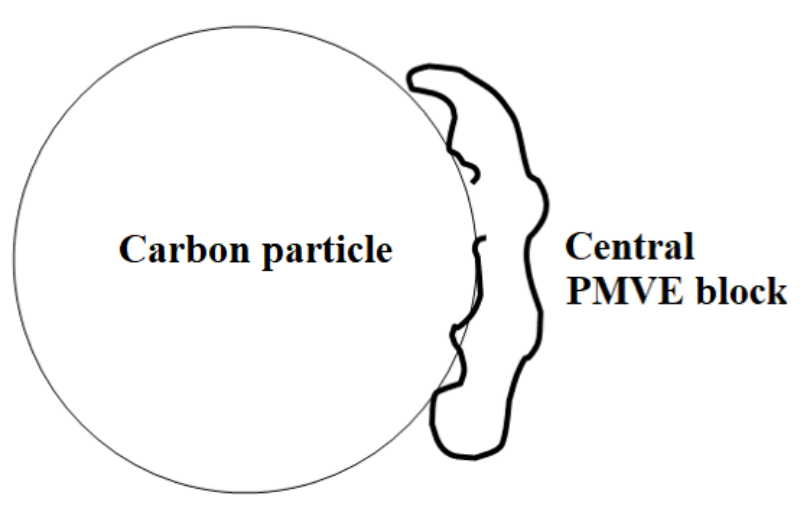

Stabilization

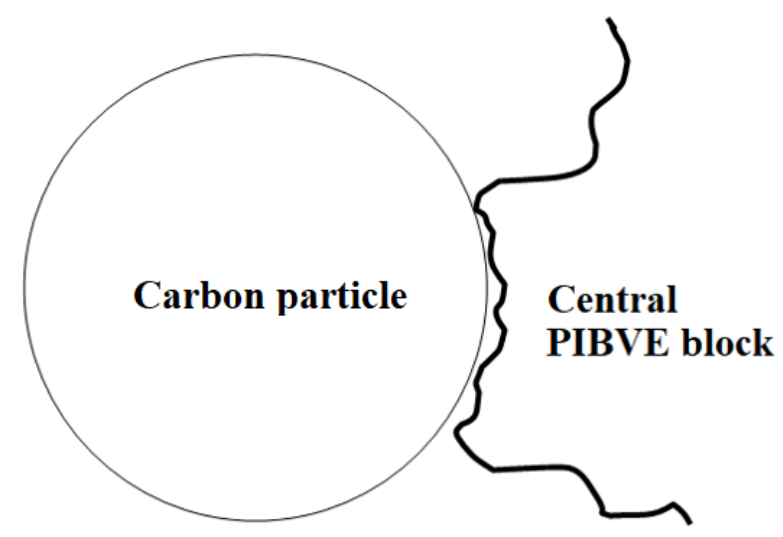

Destabilization

Fig. 2. Schematic representation of triblock copolymer adsorption on the carbon particle surface in aqueous dispersions.

From the Fig. 2 it is clearly seen, that in this case, the central hydrophilic block "covers" the hydrophobic blocks lying on the surface of the pigment and thus provides a twolayer diphilic structure. In the case of a central hydrophobic block, the hydrophilic edges stretch freely into the aqueous phase without covering the central block, which in this case is in contact with water, which is energetically disadvantageous for the system.

Summarizing the above results, one can conclude that the application of vinyl methyl ether copolymers with tailored structure and composition can provide a new alternative as a technique for stabilization of aqueous dispersion of hydrophobic particles. Development of new synthetic strategies for creation of polymers with peculiar molecular architecture gives prospective for further achievements in particle surface modification.

\section{CONCLUSION}

Thus, the results of the experiments performed show the possibility of stabilizing aqueous dispersed systems of soot with block copolymers of methyl vinyl ether with simultaneous ultrasonic treatment. It was also found that the surface-active properties of the studied copolymers strongly depend on their composition and structure. An optimal composition for twoblock copolymers and an optimal structure for three-block copolymers have been found; a number of assumptions have been made about the mechanism of the stabilizing effect of the studied block copolymers.

\section{REFERENCES}

[1] N. A. Bulychev, A. V. Ivanov, "Study of Nanostructure of Polymer Adsorption Layers on the Particles Surface of Titanium Dioxide," International Journal of Nanotechnology, vol. 16 , nos. 6/7/8/9/10, pp. $356-365$, 2019.

[2] L. N. Rabinskiy, S. A. Sitnikov, "Development of technologies for obtaining composite material based on silicone binder for its further use in space electric rocket engines," Periodico Tche Quimica, 15(Special Issue 1), pp. 390-395, 2018.

[3] N. A. Bulychev, A. V. Ivanov, "Nanostructure of OrganicInorganic Composite Materials Based on Polymer Hydrogels," International Journal of Nanotechnology, vol. 16, nos. 6/7/8/9/10, pp. $344-355,2019$.

[4] O. A. Pashkov, "Influence of Polymer Coatings on the Mechanical Properties of Steel Samples in Tensile and Bending Tests," Studies in Systems, Decision and Control, to be published.

[5] O. A. Pashkov, "Investigation of the Effect of Steel Plate Size and Elevated Temperature on Critical Load in Stability Tests," Studies in Systems, Decision and Control, to be published.

[6] O. A. Pashkov, "Theoretical calculation of the thickness of interphase zones in the Al-Al2O3 composite," Studies in Systems, Decision and Control, to be published.

[7] O. A. Pashkov, "Experimental and Theoretical Study of Mechanical Properties of Matrix Composite Materials," Studies in Systems, Decision and Control, to be published.

[8] I. P. Lifanov, A. N. Astapov, V. S. Terentieva, "Deposition of heat-resistant coatings based on the $\mathrm{ZrSi} 2-$ MoSi2-ZrB2 system for protection of non-metallic composite materials in high-speed high-enthalpy gas flows," Journal of Physics: Conference Series, vol. 1713, no. 1, pp. 012025, 2020.

[9] I. P. Lifanov, A. A. Yurishcheva, A. N. Astapov, "Hightemperature protective coatings on carbon composites," Russian Engineering Research, vol. 39, no. 9, pp. 804 808, 2019.

[10] A. N. Astapov, I. P. Lifanov, M. V. Prokofiev, "Hightemperature interaction in the $\mathrm{ZrSi} 2-\mathrm{ZrSiO} 4$ system and its mechanism," Russian Metallurgy (Metally), no. 6, pp. $640-646,2019$.

[11] N. A. Bulychev, E. L. Kuznetsova, V. V. Bodryshev, L. N. Rabinskiy, "Nanotechnological aspects of temperaturedependent decomposition of polymer solutions," Nanoscience and Technology: An International Journal, vol. 9 (2), pp. 91-97, 2018.

[12] N. A. Bulychev, L. N. Rabinskiy, "Ceramic nanostructures obtained by acoustoplasma technique," Nanoscience and 
Technology: An International Journal, 10 (3), pp. 279286, 2019.

[13]O. A. Butusova, "Surface Modification of Titanium Dioxide Microparticles Under Ultrasonic Treatment," International Journal of Pharmaceutical Research, vol. 12, i. 4, pp. 2292-2296, 2020.

[14] O. A. Butusova, "Stabilization of Carbon Microparticles by High-Molecular Surfactants," International Journal of Pharmaceutical Research, vol. 12, Supplementary Issue 2, pp. 1147-1151, 2020.

[15] Yu. V. Ioni, A. Ethiraj, "New Tailor-Made Polymer Stabilizers for Aqueous Dispersions of Hydrophobic Carbon Nanoparticles," International Journal of Pharmaceutical Research, vol. 12, i. 4, pp. 3443-3446, 2020.

[16] Yu. V. Ioni, "Nanoparticles of noble metals on the surface of graphene flakes," Periodico Tche Quimica, vol. 17, no. 36, pp. 1199-1211, 2020.

[17] O. A. Butusova, "Vinyl Ether Copolymers as Stabilizers of Carbon Black Suspensions," International Journal of Pharmaceutical Research, vol. 12, Supplementary Issue 2, pp. 1152-1155, 2020.

[18]M. O. Kaptakov, "Catalytic Desulfuration of Oil Products under Ultrasonic Treatment," International Journal of Pharmaceutical Research, vol. 12, Supplementary Issue 2, pp. 1838-1843, 2020.

[19]B. A. Garibyan, "Enhancement of Mechanical Properties of Inorganic Glass under Ultrasonic Treatment," International Journal of Pharmaceutical Research, vol. 12, Supplementary Issue 2, pp. 1829-1832, 2020.

[20]M. O. Kaptakov, "Enhancement of Quality of Oil Products under Ultrasonic Treatment," International Journal of Pharmaceutical Research, vol. 12, Supplementary Issue 2, pp. 1851-1855, 2020.

[21]O. A. Butusova, "Adsorption Behaviour of Ethylhydroxyethyl Cellulose on the Surface of Microparticles of Titanium and Ferrous Oxides," International Journal of Pharmaceutical Research, vol. 12, Supplementary Issue 2, pp. 1156-1159, 2020.

[22]B. A. Garibyan, "Mechanical Properties of Electroconductive Ceramics," International Journal of Pharmaceutical Research, vol. 12, Supplementary Issue 2, pp. 1825-1828, 2020.

[23]M. O. Kaptakov, "Effect of Ultrasonic Treatment on Stability of $\mathrm{TiO}_{2}$ Aqueous Dispersions in Presence of Water-Soluble Polymers," International Journal of Pharmaceutical Research, vol. 12, Supplementary Issue 2, pp. 1821-1824, 2020.

[24] Yu. V. Ioni, "Synthesis of Metal Oxide Nanoparticles and Formation of Nanostructured Layers on Surfaces under Ultrasonic Vibrations," International Journal of Pharmaceutical Research, vol. 12, i. 4, pp. 3432-3435, 2020.

[25] Yu. V. Ioni, A. Ethiraj, "Study of Microparticles Surface Modification by Electrokinetic Potential Measuring," International Journal of Pharmaceutical Research, vol. 12, i. 4, pp. 3436-3439, 2020.
[26] Yu. V. Ioni, "Effect of Ultrasonic Treatment on Properties of Aqueous Dispersions of Inorganic and Organic Particles in Presence of Water-Soluble Polymers," International Journal of Pharmaceutical Research, vol. 12, i. 4, pp. 3440-3442, 2020.

[27] N. A. Bulychev, L. N. Rabinskiy, O. V. Tushavina, "Effect of intense mechanical vibration of ultrasonic frequency on thermal unstable low-temperature plasma," Nanoscience and Technology: An International Journal, 11 (1), pp. 15-21, 2020.

[28]N. A. Bulychev, A. V. Ivanov, "Effect of vibration on structure and properties of polymeric membranes," International Journal of Nanotechnology, vol. 16, nos. 6/7/8/9/10, pp. $334-343,2019$.

[29] A. N. Astapov, E. L. Kuznetsova, L. N. Rabinskiy, "Operating capacity of anti-oxidizing coating in hypersonic flows of air plasma," Surface Review and Letters, 26(2), pp.1850145, 2019.

[30]L. N. Rabinskiy, O. V. Tushavina, E. I. Starovoitov, "Study of thermal effects of electromagnetic radiation on the environment from space rocket activity," INCAS Bulletin, 12 (Special Issue), pp. 141-148, 2020.

[31] A. V. Babaytsev, A. A. Orekhov, L. N. Rabinskiy, "Properties and microstructure of AlSi10Mg samples obtained by selective laser melting," Nanoscience and Technology: An International Journal, 11(3), pp. 213222, 2020.

[32] N. A. Kucheva, "Investigation of the mechanical properties of heat-protective highly porous composite materials using the effective medium model," Studies in Systems, Decision and Control, to be published.

[33] O. V. Egorova, Y. K. Kyaw, "Solution of inverse nonstationary boundary value problems of diffraction of plane pressure wave on convex surfaces based on analytical solution," Journal of Applied Engineering Science, 18(4), pp. 676-680, 2020.

[34]A. N. Tarasova, "Vibration-based Method for Mechanochemical Coating Metallic Surfaces," International Journal of Pharmaceutical Research, vol. 12, Supplementary Issue 2, pp. 1160-1168, 2020.

[35]A. N. Tarasova, "Effect of Reagent Concentrations on Equilibria in Water-Soluble Complexes," International Journal of Pharmaceutical Research, vol. 12, Supplementary Issue 2, pp. 1169-1172, 2020.

[36]A. N. Tarasova, "Effect of Vibration on Physical Properties of Polymeric Latexes," International Journal of Pharmaceutical Research, vol. 12, Supplementary Issue 2, pp. 1173-1180, 2020.

[37] V. F. Formalev, E. M. Kartashov, S. A. Kolesnik, "On the Dynamics of Motion and Reflection of Temperature Solitons in Wave Heat Transfer in Limited Regions," Journal of Engineering Physics and Thermophysics, 93(1), pp. 10-15, 2020.

[38] V. F. Formalev, N. A. Bulychev, E. L. Kuznetsova, S. A. Kolesnik, "The Thermal State of a Packet of Cooled Microrocket Gas-Dynamic Lasers," Technical Physics Letters, 46(3), pp. 245-248, 2020. 
[39] L. N. Rabinskiy, O. V. Tushavina, V. F. Formalev, "Mathematical modeling of heat and mass transfer in shock layer on dimmed bodies at aerodynamic heating of aircraft," Asia Life Sciences, (2), pp. 897-911, 2019.

[40]B. A. Antufev, O. V. Egorova, L. N. Rabinskiy, "Quasistatic stability of a ribbed shell interacting with moving load," INCAS Bulletin, 11, pp. 33-39, 2019.

[41] V. V. Bodryshev, A. V. Babaytsev, L. N. Rabinskiy, "Investigation of processes of deformation of plastic materials with the help of digital image processing," Periodico Tche Quimica, 16(33), pp. 865-876, 2019.

[42] L. N. Rabinskiy, E. L. Kuznetsova, "Analytical and numerical study of heat and mass transfer in composite materials on the basis of the solution of a stefan-type problem," Periodico Tche Quimica, 15 (Special Issue 1), pp. 339-347, 2018.

[43] O. A. Butusova, "Chemical and Physical Properties of Magnetic Composite Materials," Studies in Systems, Decision and Control, to be published.

[44] O. A. Butusova, "Investigation of Adsorption Capacity of Magnetic Sorbents for Medical Application," Studies in Systems, Decision and Control, to be published.

[45]L. N. Rabinskii, O. V. Tushavina, "Composite Heat Shields in Intense Energy Fluxes with Diffusion," Russian Engineering Research, 39(9), pp. 800-803, 2019.

[46] L. N. Rabinskiy, O. V. Tushavina, "Investigation of the influence of thermal and climate effects on the performance of tiled thermal protection of spacecraft," Periodico Tche Quimica, 16(33), pp. 657-667, 2019.

[47]M. O. Kaptakov, "Enhancement of Physical and Mechanical Properties of Metal Surfaces Coated by Polymers," Studies in Systems, Decision and Control, to be published.

[48] B. A. Garibyan, "Determination of the Elastic Modulus of the Coating Using a Spherical Indenter," Studies in Systems, Decision and Control, to be published.

[49] M. O. Kaptakov, "Calculation of Physical and Mechanical Parameters of Metal Samples with Polymer Layers," Studies in Systems, Decision and Control, to be published.

[50]B. A. Garibyan, "Theoretical Estimations of Influence of Polymer Coatings on the Elastic Modulus and Ultimate Strength of Steel Samples," Studies in Systems, Decision and Control, to be published.

[51]M. O. Kaptakov, "Numerical and Analytical Study of Mechanical Characteristics of Nanocomposites Based on Carbon Additives," Studies in Systems, Decision and Control, to be published.

[52] M. O. Kaptakov, "Synthesis and Investigation of Composite Materials Reinforced with Carbon Wires," Studies in Systems, Decision and Control, to be published.

[53] V. N. Dobryanskiy, L. N. Rabinskiy, O. V. Tushavina, "Experimental finding of fracture toughness characteristics and theoretical modeling of crack propagation processes in carbon fiber samples under conditions of additive production," Periodico Tche Quimica, 16(33), pp. 325-336, 2019.

[54] L. N. Rabinskiy, O. V. Tushavina, "Problems of land reclamation and heat protection of biological objects against contamination by the aviation and rocket launch site," Journal of Environmental Management and Tourism, 10(5), pp. 967-973, 2019.

[55] V. N. Dobryanskiy, L. N. Rabinskiy, O. V. Tushavina, "Validation of methodology for modeling effects of loss of stability in thin-walled parts manufactured using SLM technology," Periodico Tche Quimica, 16(33), pp. 650656, 2019.

\section{Contribution of Individual Authors to the Creation of a Scientific Article (Ghostwriting Policy)}

A. Perchenok carried out the synthesis of polymers.

E. Suvorova characterized the polymers.

A. Farmakovskaya has executed the experiments on dispersion stability.

V. Kohlert studied the surface activity of the polymers.

Creative Commons Attribution License 4.0 (Attribution 4.0 International, CC BY 4.0)

This article is published under the terms of the Creative Commons Attribution License 4.0

https://creativecommons.org/licenses/by/4.0/deed.en_US 